\title{
SIX YEARS OF TURKEY VULTURE WING-TAGGING
}

C. STUART HOUSTON, 863 University Drive, Saskatoon, SK S7N 0J8,E-mail: <stuart.houston@usask.ca>; BRENTON TERRY, 64 MacLean Crescent, Saskatoon, SK S7J 3R7; MARTEN J. STOFFEL, Box 183, RR\#4, SASKATOON, SK S7K 3J7; and MICHAEL BLOM, 875 Wedgewood Court, Peterborough, ON K9J 7 T8.

Since 2003, we have fitted 347 nestling Turkey Vultures with patagial (wing) tags (Table 1). The subsequent locations of sightings of wing-tags, often substantiated by photographs, provide intriguing information. Two were recorded at the Maracaibo Zoo in Venezuela, 5658 and $5696 \mathrm{~km}$ from the nest of origin. The first had been photographed at the zoo at 2 years of age on 8 November 2005; the zoo location was mapped in Figure 1 of Houston et al. ${ }^{2}$ On 14 November 2008, a second vulture reached the same zoo, 3 months after tagging, when it was about 5 months old. These two are each shown with an asterisk in Table 1.
Four North American recoveries of dead vultures (one each at 3 years and 2 years and two at 1 year, all of them tagged in 2005;) and 25 North American sightings of 18 live vultures occurred 1 to 5 years after tagging (Table 1). Six vultures were sighted outside of Saskatchewan: two in Alberta, one in Manitoba, and one each in Montana, North Dakota, and South Dakota (Fig. 1). The vulture sighted in Montana at 2 years also became the fifth double sighting when it returned to Saskatchewan, only $36 \mathrm{~km}$ from its nest of origin, at 3 years.

The remaining four multiple sightings were reported only within

Table 1: Numbers of nestling Turkey Vultures $(n=24),>1$ year or $>4000 \mathrm{~km}$, tagged each year, with numbers encountered in subsequent years. To calculate $\%$ nestlings encountered, each vulture was counted only once.

\begin{tabular}{|c|c|c|c|c|c|c|c|c|c|c|c|}
\hline Year & $\begin{array}{c}\# \\
\text { nests }\end{array}$ & $\begin{array}{c}\# \\
\text { tagged }\end{array}$ & $\begin{array}{c}>4000 \mathrm{~km} \\
<1 \mathrm{yr}\end{array}$ & $1 \mathrm{yr}$ & $2 \mathrm{yr}$ & $3 y r$ & $4 \mathrm{yr}$ & $5 y r$ & $\begin{array}{c}\text { Total \# } \\
\text { encountered }\end{array}$ & $\begin{array}{c}\text { Total \# } \\
\text { individuals }\end{array}$ & $\begin{array}{c}\% \\
\text { individuals }\end{array}$ \\
\hline 2003 & 9 & 14 & & 1 & $1^{*}$ & 1 & 1 & $2^{+}$ & 6 & 4 & 29 \\
\hline 2004 & 17 & 30 & & 2 & 1 & 1 & 4 & & 8 & 5 & 17 \\
\hline 2005 & 29 & 43 & & 3 & 2 & 3 & & & 8 & 7 & 16 \\
\hline 2006 & 46 & 84 & & 4 & 2 & & & & 6 & 6 & 7 \\
\hline 2007 & 43 & 78 & & 1 & & & & & 1 & 1 & 1 \\
\hline 2008 & 56 & 98 & $1^{*}$ & & & & & & 1 & 1 & 1 \\
\hline TOTAL & 200 & 347 & 1 & 11 & 6 & 5 & 5 & 2 & 30 & 24 & 7 \\
\hline \multicolumn{4}{|c|}{${ }^{\star}=$ in Venezuela } & \multicolumn{8}{|c|}{${ }^{+}=$two sightings, nearly 3 months apart, of second bird at $5 \mathrm{yr}$} \\
\hline
\end{tabular}

67 (1) March 2009 


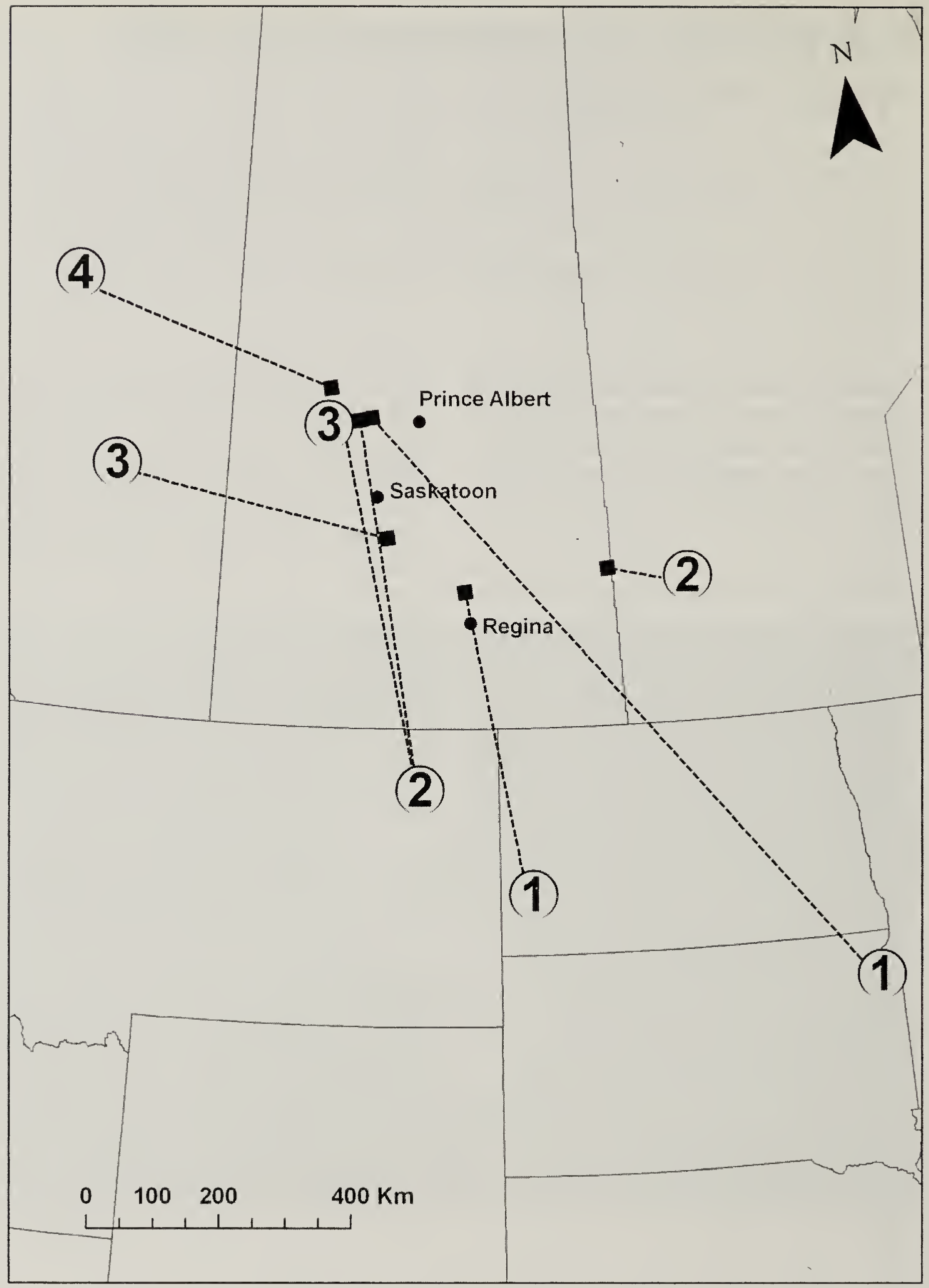

Figure 1. Vulture wing tags (6) sighted outside Saskatchewan, but omitting two sighted in Venezuela. Nest of origin is a square; the number within the circle indicates the number of years elapsed before the sighting at that point. The dotted line is diagrammatic and does not represent the route of travel during the elapsed year(s). The vulture sighted in Montana at 2 years had returned to within $36 \mathrm{~km}$ of its nest of origin at 3 years.

Kathy M. Meeres 
(4)

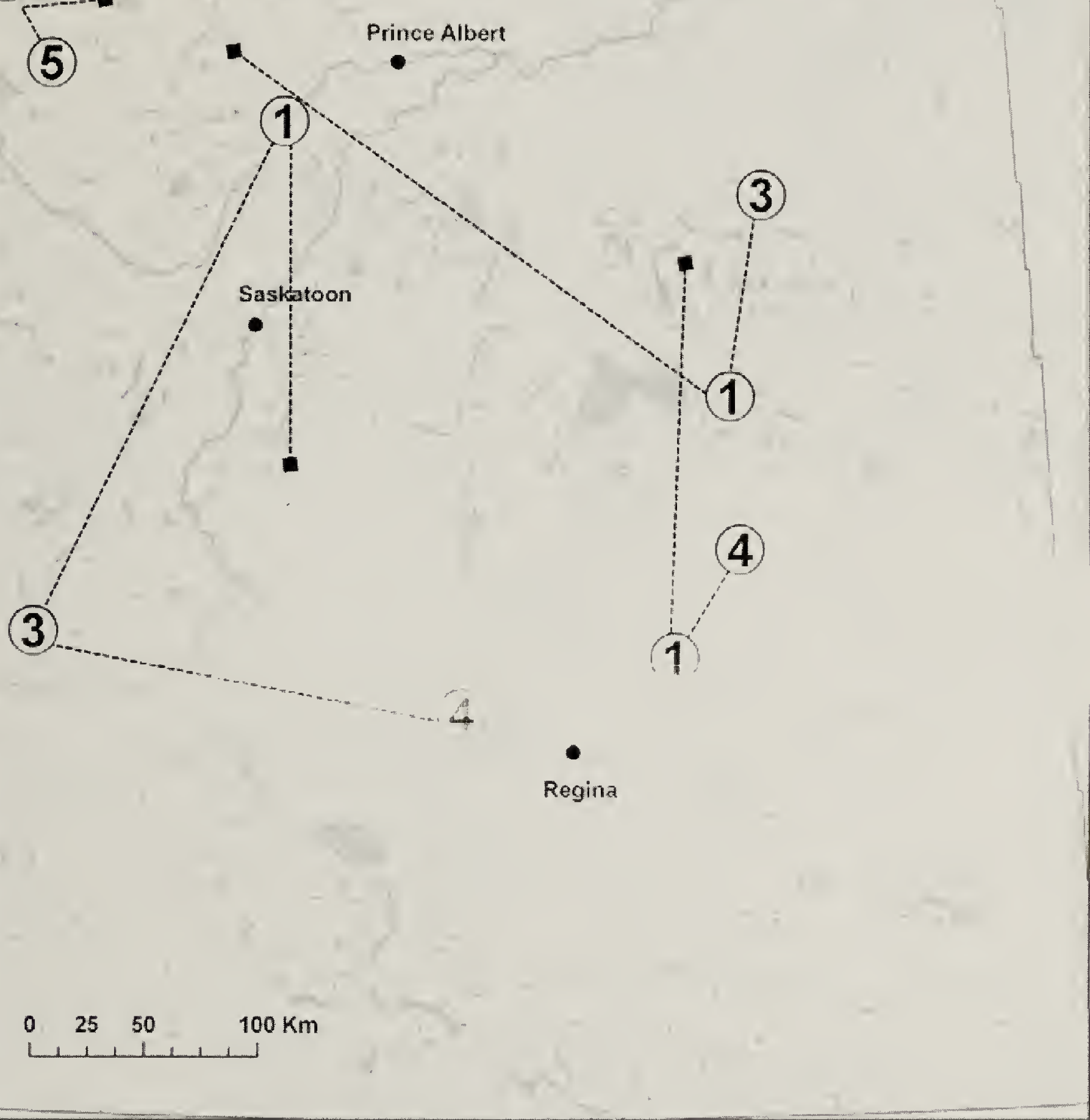

Figure 2. Vulture wing-tags (4) sighted $>1$ year, more than once.

Kathy M. Meeres.

Saskatchewan. Of these, three were encountered two times: from a nest at Bapaume to Cater at 4 years and Robinhood at 5 years; from Mont Nebo to Fishing Lake at 1 year and Chelan at 3 years; and from Archerwill to Fort Qu'Appelle at 1 year and Ituna at 4 years. The fourth was encountered three times, from a nest at Hanley north to Shellbrook at 1 year, south to Kyle at 3 years, and east to Buffalo Pound Lake at 4 years (Fig. 2). On 12 occasions, 12 different vultures were encountered once each at 5,4 , and 3 years; three at 2 years, and six at 1 year (Fig. 3). 


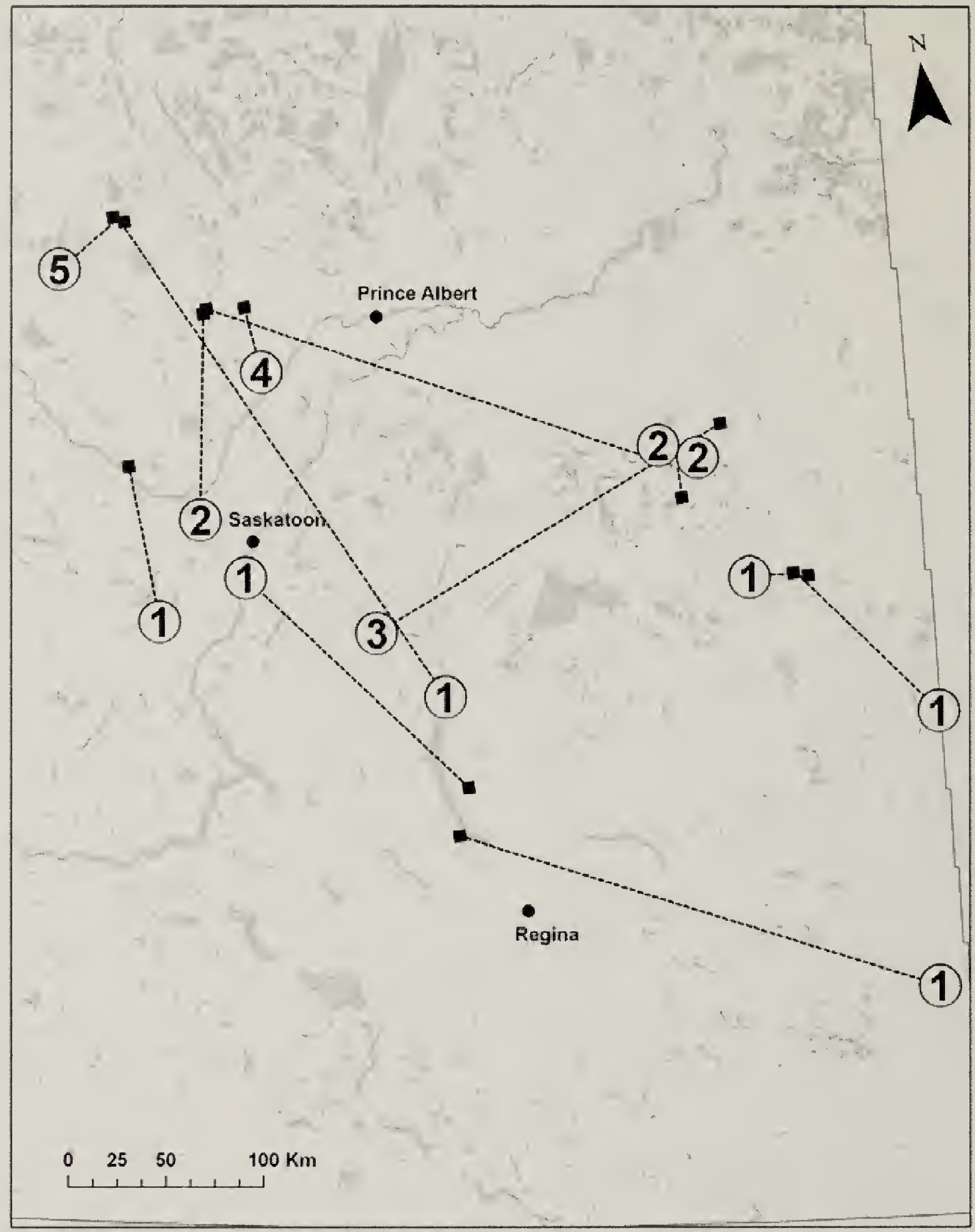

Figure 3. Vulture wing-tags (12) sighted $>1$ year, only once.

Kathy M. Meeres.

The percentage of encounters increased with years elapsed since tagging (Table 1), which is opposite to other studies of marked birds, where sighting numbers typically are halved each consecutive year after marking (e.g., Great Horned Owls ${ }^{1}$ ). To explain sightings increasing in frequency with age, one might postulate that many vultures, 1 and 2 years after tagging, do not return to or near Saskatchewan, where the public is more likely to be aware of vulture tagging and to whom to report. Tagged vultures sighted at 1 year were an average of $267 \mathrm{~km}$ from their nest of origin $(n=12)$. This distance declined to $210 \mathrm{~km} \quad(\mathrm{n}=5)$ in the second year, $207 \mathrm{~km}(n=5)$ in the 
third year, $147 \mathrm{~km}(\mathrm{n}=5)$ in the fourth year, and $37 \mathrm{~km}(\mathrm{n}=3)$ in the fifth year. In Wisconsin, a 10-year (1983-1993) study of wing-tagged vultures showed that "if a fledgling eventually returns ... it typically makes its reappearance during its third year" (Michael J. Mossman, pers. comm.).

Readers should be on the watch for tagged vultures, as tagged examples of these long-lived birds increase in numbers each year. We will watch closely in 2009 and 2010 for evidence that this species can begin breeding as early as 6 or 7 years; the only breeding Turkey Vulture of known age in North America to date was 11 years old. ${ }^{3}$ That vulture, LeftGreen-11, probably hatched in late May 1986, was tagged in July, and fledged in August 1986. It did not return until 15 April 1989 , just short of 3 years of age. On 2
June 1997, this vulture was an adult on two eggs in a different outcrop nest, only $1.2 \mathrm{~km}$ from its natal site, at or near 11 years of age (Michael $\mathrm{J}$. Mossman, pers. comm.)

\section{Acknowledgements}

We thank Kathy M. Meeres for preparing all three maps and Michael J. Mossman for additional information concerning the breeding vulture of known age.

1. HOUSTON, C.S. 1978. Recoveries of Saskatchewan-banded Great Horned Owls. Canadian Field-Naturalist 92:61-66.

2. HOUSTON, C.S., G.L. HOLROYD, B. TERRY, M. BLOM, and M.J. STOFFEL. 2007. Tracking Saskatchewan nestling Turkey Vultures. Blue Jay 65:201-207.

3. KIRK, D.A. and M.J. MOSSMAN. 1998. Turkey Vulture (Cathartes aura). Birds of North America \#339.

\section{SPRING}

April has its way

does what it will with spring-

blustery cold its wind

a sullen overcast its skies

and dabs of dirty crusted snow

patched on a greasy field

Two sharp-tailed grouse

in buffs of browns-crested, sedate, alert-

step mincingly about

the hummocky stubble plowed last fall

toe the mud and snow and bleached and matted straw

for food, here better fare

than winter's sparse lean peckings

Two meadowlarks

arrivals from the south

drop in, all unannounced

at once assume they're fellow grouse

or quail-like cousins

stride and weave among the larger birds

their tails a-flick, their knowing beaks

poking likely spots for seeds or bugs

their striking yellow breasts a sign of spring

a sudden warm world's welcome to the season

-Victor C. Friesen 